\title{
Operant Discriminative Learning and Evidence of Subtelencephalic Plastic Changes after Long-Term Detelencephalation in Pigeons
}

\author{
S.M. Cerutti ${ }^{1,3}$ S. Diaz-Cintra, ${ }^{2}$ L. Cintra, ${ }^{2}$ and E.A.M. Ferrari ${ }^{1}$ \\ ${ }^{1}$ Laboratório de Sistemas Neurais e Comportamento, Departamento de Fisiologia e Biofisica, \\ Instituto de Biologia, Universidade Estadual de Campinas, UNICAMP; ${ }^{2}$ Instituto de Neurobiologia, \\ Departamento de Neurobiologia Del Desarrollo Y Neurofisiologia, Universidad Nacional Autónoma \\ de México, México; ${ }^{3}$ Laboratório de Plasticidade Neural-Programa de Pós-Graduandos em \\ Ciências Farmacêuticas- PROPEP - Universidade São Francisco-Bragança Paulista,SP
}

\begin{abstract}
We analyzed operant discrimination in detelencephalated pigeons and neuroanatomical substrates after long-term detelencephalation. In Experiment I, experimental pigeons with massive telencephalic ablation and control pigeons were conditioned to key peck for food. Successive discrimination was made under alternating red (variable-ratio reinforcement) and yellow (extinction) lights in one key of the chamber. These relations were interchanged during reversal discrimination. The sessions were run until steady-state rates were achieved. Experiment II analyzed the morphology of the nucleus rotundus and optic tectum in long-term detelencephalated and control birds, using a Klüver-Barrera staining and image analyzer system. Detelencephalated birds had more training sessions for response shaping and steady-state behavior $(\mathbf{p}<0.001)$, higher red key peck rates during discrimination $(p<0.01)$, and reversal discrimination indexes around 0.50 .

Reprint requests to: Elenice A.M. Ferrari, Departamento de Fisiologia e Biofísica, Instituto de Biologia, UNICAMP, Cidade Universitária Prof. Zeferino Vaz, fax 019-3788-6185, tel 019-37886205, 13083-970, Campinas, SP, Brasil; e-mail: elenice(a)obelix.unicamp.br
\end{abstract}

Morphometric analysis revealed a decreased number of neurons and increased vascularity, associated with increases in the perimeter $(p<0.001)$ in the nucleus rotundus. In the optic tectum, increases in the perimeter $(p<0.05)$ associated with disorganization in the layers arrangement were seen. The data indicate that telencephalic systems might have an essential function in reversal operant discrimination learning. The structural characteristics of subtelencephalic systems after long-term detelencephalation evidence plastic changes that might be related to functional mechanisms of learning and neural plasticity in pigeons.

\section{KEYWORDS}

operant discrimination, telencephalon, pigeons, massive lesion, reversal learning, nucleus rotundus, optic tectum

\section{INTRODUCTION}

The analysis of lesion-induced changes in nervous tissue is often referred to as the evaluation 
of neural plasticity in the central nervous system. Indeed, functional and structural changes in neural cells and circuits after cerebral lesions have been documented in both non-human and human studies (Aldskogius \& Kozlova, 1998; Fawcett \& Ascher, 1999; Finger \& Almli, 1985; Horner \& Gage, 2000; Kolb \& Whishaw, 1989; Le Vére, 1980; Chen, et al., 2002; Riley, et al., 1988).

As well, most of our knowledge about neural plasticity is based upon the analysis of learned behavior because the assessment of functional recovery after brain lesions requires an analysis of a response class or of a pattern of behavior (Gaffan, et al., 2002; Huston \& Tomaz, 1986; Mogensen \& Divac, 1993; Stettner, 1974; Watanabe, 2001; Wesp \& Goodman, 1978; Zeier, 1968; Zeier, 1974). Within such context, the discriminative behavior provides one class of operant behavior that has been mostly used for the evaluation of the effects of brain lesion in animals, as well as in human neurorehabilitation programs (Aldavert-Vera, et al., 1999; Lawrence, et al., 1999; Salgado, et al., 2000; Watanabe, 1999).

Operant discrimination refers to differential rates of responding controlled by stimuli correlated with different probabilities of reinforcement (Andrzejewisk; et al., 2001; Mackintosh, 1977; McSweeney, et al., 2001; Mitchel, 1983; Terrace, 1966). The stimulus associated with a higher probability of reinforcement is usually referred to as a positive stimulus and the one associated with a lower probability of reinforcement is referred to as a negative stimulus. Reversal discrimination learning may be established if the previously acquired stimuli functional values are interchanged (Hartmann \& Güntürkün, 1988; McSweeney, et al., 2001; Shimizu \& Hodos, 1989). Among vertebrate animal studies, and particularly in birds, both visual and reversal discrimination learning have been widely used in the analysis of the effects of brain lesions on behavior (AldavertVera, Costa-Miserachs, et al., 1999; Bessette \&
Hodos, 1969; Cerutti \& Ferrari, 1995; Chaves \& Hodos, 1998; Colombo, et al., 2001; Csillag, 1999; Delay, 2001; Eacott, et al., 2001; Good, 1978; Hodos, 1969, 1970; Hodos, et al., 1984; Macphail, et al., 1993; Pritz, et al., 1970; Watanabe, 2001). Investigations of plasticity after brain lesioning followed by learning have used localized damage to the central nervous system. Among vertebrate studies, however, partial or total hemispherectomy have also been used in the analysis of neural reorganization, as well as in the analysis of behavior and learning (Ferrari, et al., 1999; Huston, et al., 1985; Lópes Broglio, et al., 2000; Silva \& Ferrari, 1991; Souza, et al., 1990; Toledo \& Ferrari, 1991; Tomaz \& Huston, 1986).

Actually, worth considering is that studies using massive brain lesions might be especially interesting for analyzing processes of neural plasticity, as well as providing interesting animal models of brain pathology (Finger \& Almli, 1985; Kolb \& Whishaw, 1989; Kolb \& Whishaw, 1998; Le Vère, 1980). We must consider that the extensive telencephalic lesion can be followed by a great rate of neuronal death and can result in reorganization of the remaining neuronal population as well as of its neural environment. Processes that guarantee adequate nutritional, hormonal and metabolic support together with glial-mediated mechanisms may be essential for neuronal function in the subtleencephalic structures directly affected by deletencephalation (Aldskogius \& Kozlova, 1998; Carmignoto, 2000; Cavaglia, et al., 2001; Cerutti \& Chadi, 2000; Fawcett \& Ascher, 1999; Giordana, et al., 1994; Gomes, et al., 2001; Granados-Hojas, et al., 2002; Jegling, et al., 1995; Saadoun, et al., 2002). The kind of anatomical and functional reorganization that may occur in these structures after extensive damage of their telencephalic targets still requires systematic analysis. Also necessary is the elucidation of issues related to the ways in which these remaining subtelencephalic structures might account for the processes of acquisition, 
consolidation, and retrieval of learned information. Especially, as far as visual discrimination learning is concerned, it is reasonable to ponder how the subtelencephalic visual relay stations might operate in the absence of their primary cortical targets. Taken together, this information makes detelencephalated animals unique as a model for analyzing the morphological and functional status of subtelencephalic structures in brains devoid of telencephalon.

Indeed, such reasoning provided the rationale for previous investigations of the behavioral and learning capacities of detelencephalated pigeons in our laboratory (Cerutti \& Ferrari, 1995; Ferrari, et al., 1999; Silva \& Ferrari, 1991; Souza, et al., 1990; Toledo \& Ferrari, 1991). The data from those studies are directly related to prior reports relating to the telencephalic functions and the neural organization of behavior and learning in pigeons (Mitchel, 1983; Stettner, 1974; Zeier, 1974) as well as in rats (Huston, et al., 1985; Tomaz \& Huston, 1986) and in humans (Bertson, et al., 1983; Lawrence, et al., 1999). Besides raising questions about the role of subtelencephalic structures in learning and memory, such studies using pigeons as the subject provide a useful tool favoring comparative analysis.

The present paper extends our previous work with two main purposes. First, Experiment 1 intended to characterize the operant behavior of pigeons trained in discrimination and reversal learning after massive telencephalic lesion. Second, Experiment 2 aimed to characterize the aspects of morphological reorganization in subtelencephalic structures after long-term detelencephalation in pigeons. Neurophysiological evidence points to the optic tectum as an important integrative system for both the thalamofugal and the tectofugal avian visual pathways (Britto, 1978; Güntürkün \& Hahmann, 1999; Hellmann \& Güntürkün, 1999; Hodos \& Bonbright, 1974; Karten, et al., 1997; Revzin \& Karten, 1967; Shimizu \& Bowers, 1999). The major source of tectal efferents is the nucleus rotundus, a thalamic component of the tectofugal pathway (Heidmann \& Lucksch, 2001; Hellmann \& Güntürkün, 1999; Hodos, et al., 1984; Hunt \& Künzle, 1976; Karten \& Hodos, 1970; Karten \& Revzin, 1960; Shade \& Powers, 1969), and is well established as a nucleus that is involved in discrimination learning (Hodos, 1969; Hodos \& Karten, 1966; Güntürkün et al, 2000; Hodos, 1969; Hodos \& Bonbright, 1974; Laverghetta \& Shimizu, 1999). In this sense, we investigated the type of anatomical and functional reorganization that might occur in these structures after extensive damage of their telencephalic targets.

\section{EXPERIMENTAL}

\section{Experiment I}

Subjects. Seventeen pigeons, averaging $300 \mathrm{~g}$ in weight and $20 \mathrm{~cm}$ in height, were housed in individual cages and maintained at $80 \%$ of the ad libitum weight by restricted access to food, except during the post-surgery recovery period. Two groups were submitted to learning $(\mathrm{L})$ procedures: telencephalic-lesion learning (Exp, $n=8)$ and nolesion learning (Control, $\mathrm{n}=9$ ). All procedures followed the ethical recommendations described by the Brazilian Neuroscience and Behavior Society (SBNEC).

Apparatus. A standard two-key operant conditioning chamber for pigeons was used. The right response key was used as the operandum throughout the experiment. The stimuli were programmed and the responses were recorded automatically with electromechanical circuits. A stereotaxic instrument (David-Kopf) equipped with a Revzin adapter for pigeons was used during surgery. The morphometric analysis used an image analyzer system Histo2000 (BIOCOM, France), connected to a Nikon microscope and software developed by Corkidian Hirsch, UNAM, Mexico. 
Surgery procedure. Ablation of the telencephalic neural tissues was performed by the technique described in previous studies (Cerutti \& Ferrari, 1995; Ferrari, et al., 1999; Silva \& Ferrari, 1991; Souza, et al., 1990; Toledo \& Ferrari, 1991). During surgery the subjects were kept under deep anesthesia (Xilazine-ketamine $0.05 \mathrm{~mL} / 100 \mathrm{~g}$ ). After the completion of the short-lasting surgery, the birds received $5 \mathrm{~mL}$ of hypertonic saline $(0.9 \mathrm{M}$ $\mathrm{NaCl}$; i.p.) and antibiotics and then were kept in a temperature-controlled room $\left(30^{\circ} \mathrm{C}\right)$. Three times a day, the birds received directly in the beak food and water complemented with a vitamin complex (Vitagold) until the recovery of spontaneous feeding and drinking behaviors. After reaching a steady post-surgery weight, the birds were submitted to a food deprivation schedule. Training was initiated as soon as the bird reached experimental weight. After recovering their spontaneous feeding and drinking behavior, which occurred within 15-30 days after surgery, the pigeons were weighed daily for 10 days. In the next 7 days, the pigeons were submitted to a gradual food restriction schedule until they reached $80 \%$ of their ad libitum weight. The operant training began when each bird reached its experimental weight.

Operant conditioning/discrimination procedures. The sequence of operant conditioning procedures was the same for all the operated and non-operated birds. They were trained to attend to the foodhopper (magazine training) and shaped to peck the key by differential reinforcement of successive approximations to this response. Following each response, the food hopper was switched on for $30 \mathrm{~s}$. The criterion for key-peck learning was the occurrence of at least 50 reinforced key-peck responses during one session. The right key was continuously transilluminated by a red light. Following key-pecking acquisition, the reinforcement duration was gradually reduced to $6 \mathrm{~s}$ of food presentation. The birds were exposed to 10 sessions of key-pecking training in a continuous reinforce- ment (CRF) schedule and to 14 sessions in a variable-ratio schedule (VR 5:1) for food reinforcement. After this training the birds were introduced to the situation of successive discrimination.

The Yellow component was introduced in the first discrimination session with gradual increases of $5,20,30,40$, and 60 seconds. In this discrimination situation, two conditions of right-key illumination alternated every $60 \mathrm{~s}$ : the Red light indicated reinforcement in a VR 5:1 schedule; the Yellow light signaled no reinforcement for key pecking, namely, extinction (EXT). Discrimination sessions lasted for $60 \mathrm{~min}$ and were run for at least 14 sessions or until steady-state behavior was reached.

The steady-state rates were analyzed for each component of the discrimination situation, in blocks of six sessions. The steady-state criterion assumed that the difference between the mean response rates in the first three and the last three sessions of this block was not higher than $10 \%$ of the average rate of the six criterion sessions. After completing discriminative training, the pigeons were trained in reversal discrimination. In this situation, the Red light was associated with non-reinforcement, that is, extinction, and Yellow light signaled the reinforcement in the VR 5:1 schedule. The steady-state criterion was the same as that used for discrimination learning.

Perfusion. After behavioral training, the birds were deeply anesthetized with xilazine-ketamine and sacrificed by a transcardial perfusion with 100 $\mathrm{mL}$ isotonic saline, followed by $350 \mathrm{~mL} 4 \%$ parafomaldehyde in $0.1 \mathrm{M}$ phosphate buffer $(\mathrm{pH}$ 6.9). The brains were removed from the skull and post-fixed for 7 days in the fixative solution for additional fixation. After that, the brain was washed in tap water, dehydrated in a progressive ethanol series, and stored in cedar-wood oil for posterior paraffin embedding. Serial $10 \mu \mathrm{m}$ sections were obtained and used to assess the size and extension of each lesion. 
Statistical Analysis. The data relative to the number of sessions during key peck shaping were analyzed with a one-way ANOVA, with the group as the factor. An ANOVA with group, condition (Discrimination and Reversal learning), and stimulus (Red and Yellow) as factors was used for the analysis of the number of sessions and overall mean rates. Key-peck rates in each stimulus component and discrimination ratios were analyzed with an ANOVA with repeated measures, having group, condition, and stimulus as factors and session as repeated measures. Multiple posthoc comparisons used the Tukey-Kramer's test.

\section{Experiment II}

Subjects In Experiment II, we used another set of nine adult individually housed pigeons having an average weight of $300 \mathrm{~g}$ and average height of $20 \mathrm{~cm}$. The birds were distributed into two groups: telencephalic lesion (TL, $n=6$ ) and non lesioned (Control, $\mathrm{n}=3$ ).

Surgery. Surgery was carried out according to the same technique used in Experiment 1. The post-operative conditions were exactly the same as described for Experiment 1.

Perfusion. After a post-operative follow-up during 120 days, the birds were transcardially perfused as described for Experiment 1. Their brains were removed from the skull and post-fixed during 7 days in the fixative solution.

Histochemical analysis. Then the brains were washed in tap water, dehydrated in a progressive ethanol series, and stored in cedar-wood oil for posterior paraffin embedding. Serial $10 \mu \mathrm{m}$ sections were obtained at different rostrocaudal levels, including the nucleus rotundus (nRt) and the optic tectum (OT). Every tenth section was mounted, and the Klüver- Barrera technique (1953) was used for staining the neuronal bodies and myelinated axons to assess the size and localization of lesion as well as for morphometric analysis of the $\mathrm{nRt}$ and OT.

Morphometric analysis. The morphometric analysis focused on particular locations defined according to Karten and Hodos (1967) stereotaxic atlas of the pigeon brain. The structural organization of subtelencephalic components of the visual system was analyzed in long-term detelencephalated brains and non-lesioned brains. Three different levels of analysis were defined for tectofugal components: Level I sections were rostral (coordinates A-7,0; A-6,75; A-6,50) and showed only the nucleus rotundus; Level II sections were medial (A-6,25, A-5,75; A-5,25) and showed nucleus rotundus and the optic tectum; Level III sections were caudal corresponding to dorsal mesencephalon (A-4.50; A-3.0; A-0.75) and showed the optic tectum in relation to the lateral ventricles and the first view of the optic lobe. At each level, three sequential sections were analyzed for each subject.

Nucleus Rotundus analysis. A $200 \mathrm{~mm}$ mask area that was randomly projected within the area of the nucleus was defined for cellular analysis. The whole perimeter area and the number of neurons and vessels were measured.

Optic tectum analysis. Both the perimeter and the thickness of each layer were measured. The measurement of the layer thickness was considered a virtual straight line having the ventricle as its origin and reaching the lateral region of the optic tectum. The measurements were taken across the lateral portion of the layers.

Statistical analysis. Morphometric data relative to (a) the number of neurons and vessels in the nucleus rotundus; (b) the OT and nRt perimeter measures, and (c) the OT layers thickness were analyzed with a two way ANOVA with group and level (NI and NII at the nRt; NII and NII at the OT) as factors. Multiple post hoc comparisons used the Tukey-Kramer's test. 


\section{RESULTS}

\section{Histology}

Macroscopic analysis of the brains showed lesions involving both hemispheres, except for some residual tissue of the ventral archistriatal complex (see levels NI, NII and NIII, Fig. 1) and fragments of paleostriatal complex (see level NI, Fig. 1). The histological reconstructions of one hemisphere of the brain according to Karten and Hodos (1967) is presented in Fig. 1, with darkened

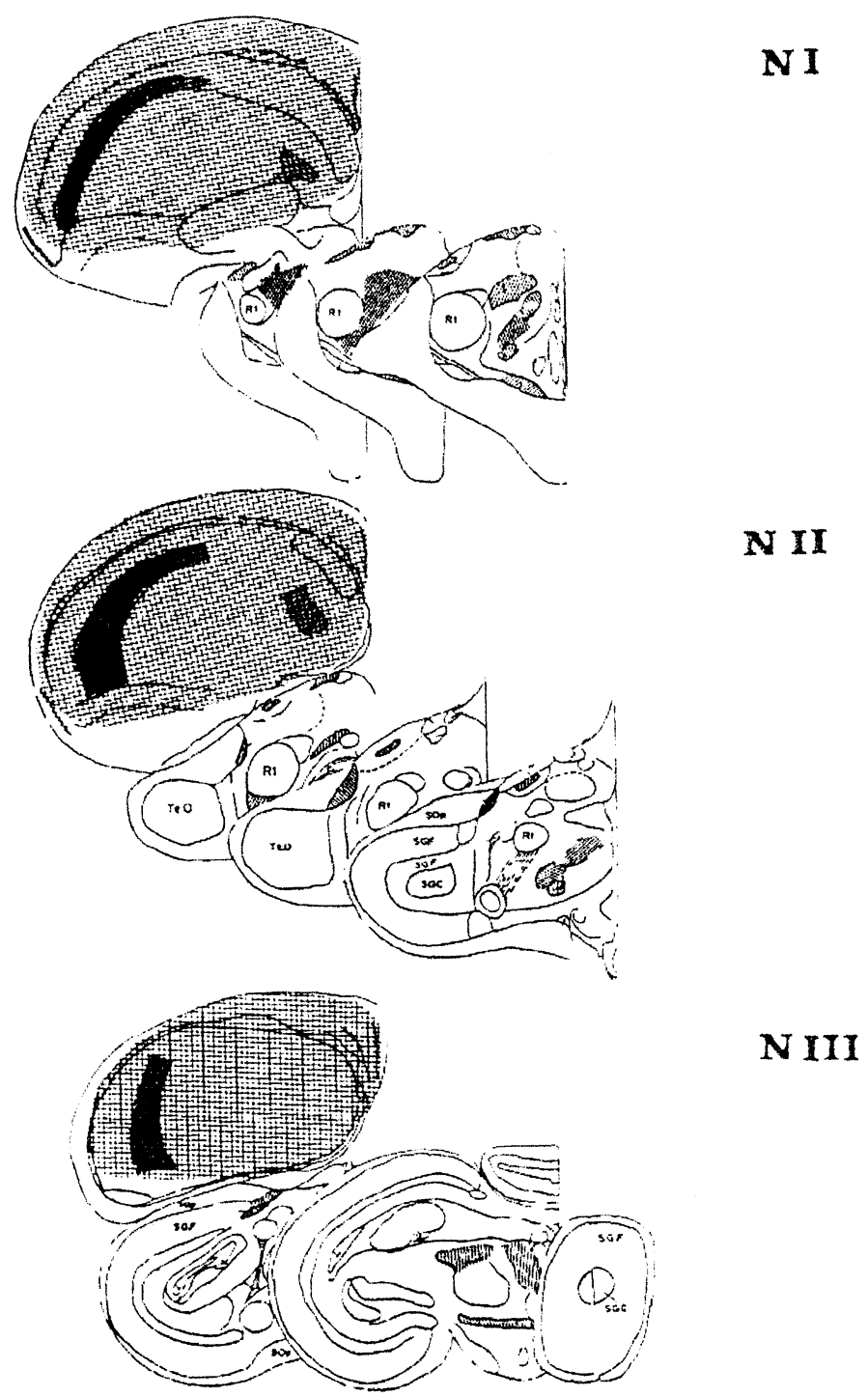

Fig. 1: Schematic drawing of histological reconstruction of one hemisphere of the brain of the pigeon (Karten \& Hodos, 1967). Darkened gray areas indicate the extension of the lesion of the telencephalon, which is also valid for the omitted hemisphere. The indications NI, NII and NIII refer to the levels defined for morphometric analysis. $\mathrm{Rt}=$ rotundus; $\mathrm{TeO}=$ optic tectum; $\mathrm{SGC}=$ Stratum griseum centrale 
areas indicating the extension of the lesion of the telencephalon. All lesions were consistent with the pattern of detelencephalation reported in previous studies and included the entire telencephalon (Cerutti \& Ferrari, 1995; Ferrari, et al., 1999; Silva \& Ferrari, 1991; Souza, et al., 1990; Toledo \& Ferrari, 1991)

\section{Behavioral Analysis}

Experimental birds were slower in the acquisition of key pecking response as compared to the controls. This was confirmed by ANOVA as a significant difference between the two groups during the response shaping condition $\left(\mathrm{F}_{1,16}=\right.$ $10.95 ; \mathrm{p}=0.004769$ ). Experimental birds also required more training sessions than the controls to show discriminative and reversal steady-state rates.

Comparisons of the number of sessions in each condition indicated a significant effect of group $\left(F_{1,15}=29.10 ; p=0.000074\right)$. The overall response rates data indicated significant variations between groups $\left(F_{1,15}=15,03 ; p=0.001491\right)$ and stimulus $\left(\mathrm{F}_{1,15}=6.13 ; \mathrm{p}=0.025739\right)$. The rates of key pecking varied as a function of the functional value of the stimulus in each condition, which may be related to the significant interaction among group, condition, and stimuli $\left(\mathrm{F}_{1,67}=8,79 ; \mathrm{p}=0.009641\right)$ showed by ANOVA (Fig. 2).
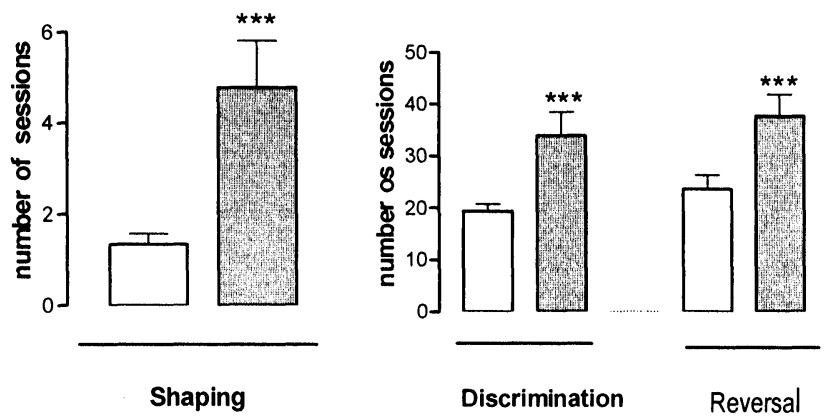

Key pecking responses

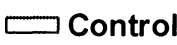
$\varpi \operatorname{Exp}$

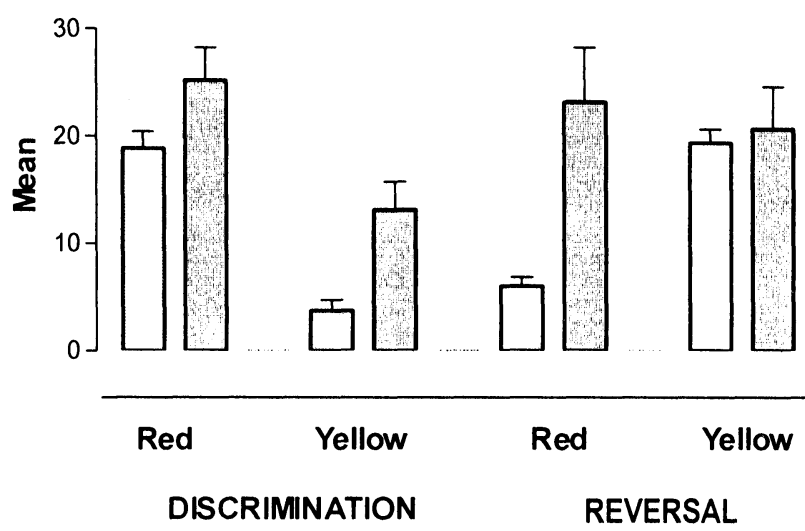

Fig. 2: Number of sessions for key pecking response shaping and for steady-state rates in the Discrimination situation, for Telencephalon-lesioned (Exp), and NonLesioned (Control) groups (Top) and mean Key pecking response during experiment I, for Red and Yellow components of the Discrimination and Reversal situation (bottom). Data are reported as overall mean number of sessions. Vertical bars indicate \pm SEM. ** $\mathrm{P}<0.01 ; * * * \mathrm{p}<0.001$, compared with control group. 


\section{Response Rate \\ Discrimination \\ Reversal}
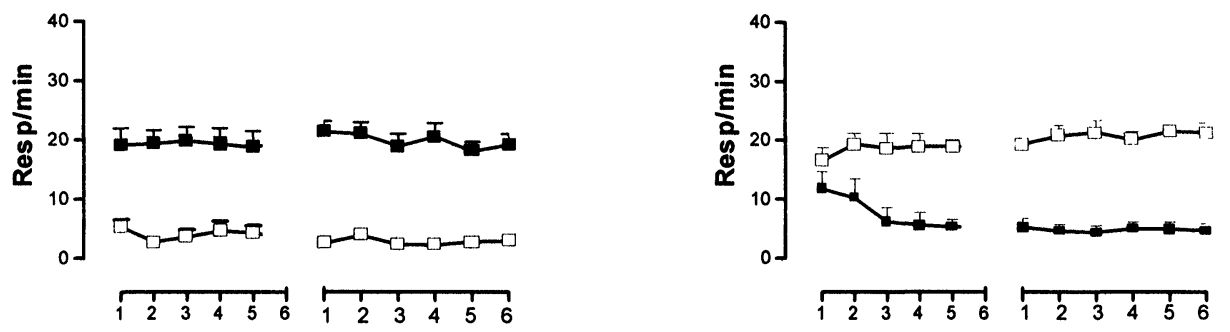

Control

$\rightarrow-$ Yellow

Exp
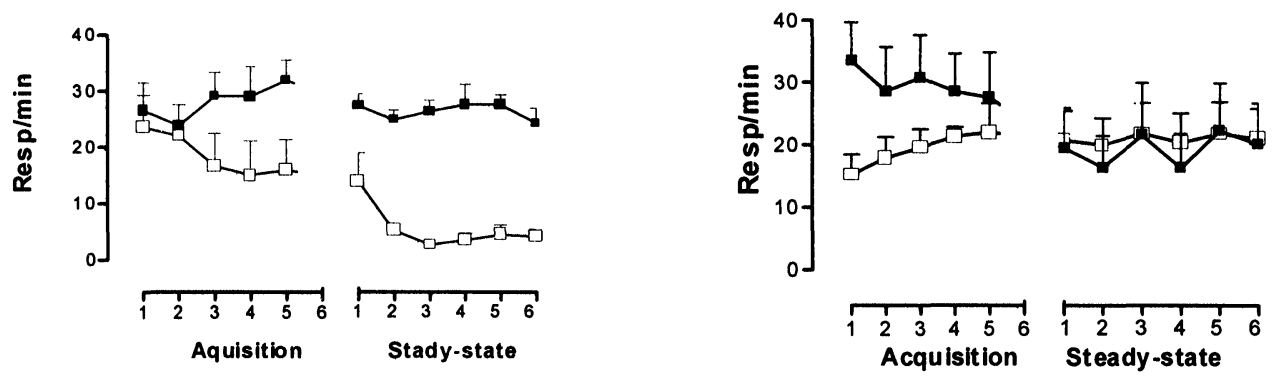

\section{Discrimination Index}
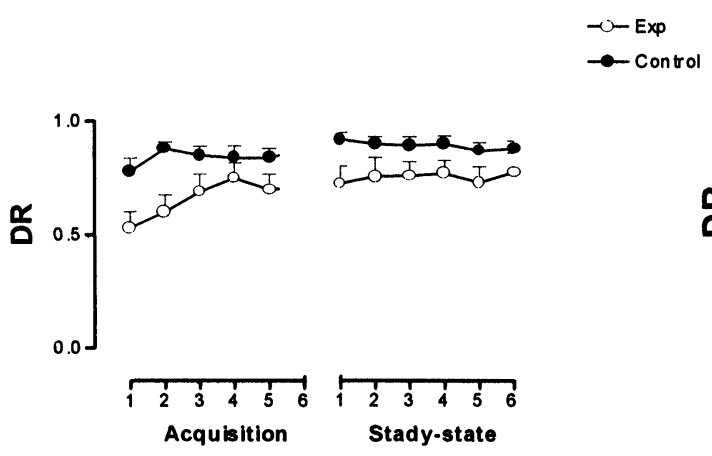

Fig. 3: Key pecking response rates in Red (square symbols) and Yellow (circle symbols) components of the Discrimination and Reversal situation, for telencephalon-lesioned (Exp) and Non-lesioned (Control) birds. Data are reported as mean group values, computed for each one of the first six training sessions (Acquisition) and the six criterion-sessions (Steady-state) (Top) Discrimination ratio (DR) expressed as relative response rates in red and yellow for Telencephalon-lesioned (Exp), Non-Lesioned (Control) groups (Botton) Vertical bars indicate \pm SEM. 
Figure 3 shows pecking rate curves in Red and Yellow components in the Discrimination and Reversal conditions. Higher variation of response rates was seen for experimental birds as compared with controls. In the discrimination condition, both groups showed differential response rates in both components.

ANOVA demonstrated significant effects of group $\left(F_{1,14}=10.72 ; p=0.005538\right)$ and stimulus
$\left(\mathrm{F}_{1,13}=56.96 ; \mathrm{p}=0.00004\right) . \mathrm{A}$ significant interaction among group, condition, session, and stimulus was found $\left(\mathrm{F}_{5,65}=4.33 ; \mathrm{p}=0.001828\right)$.

In contrast to the control birds that reversed their rates of responding in red and yellow since the second acquisition session, the experimental birds showed overlapped response rates in the two components, indicating absence of control of the reinforcement contingencies over behavior.

\section{Nucleus Rotundus}

\section{Number of Neurons}
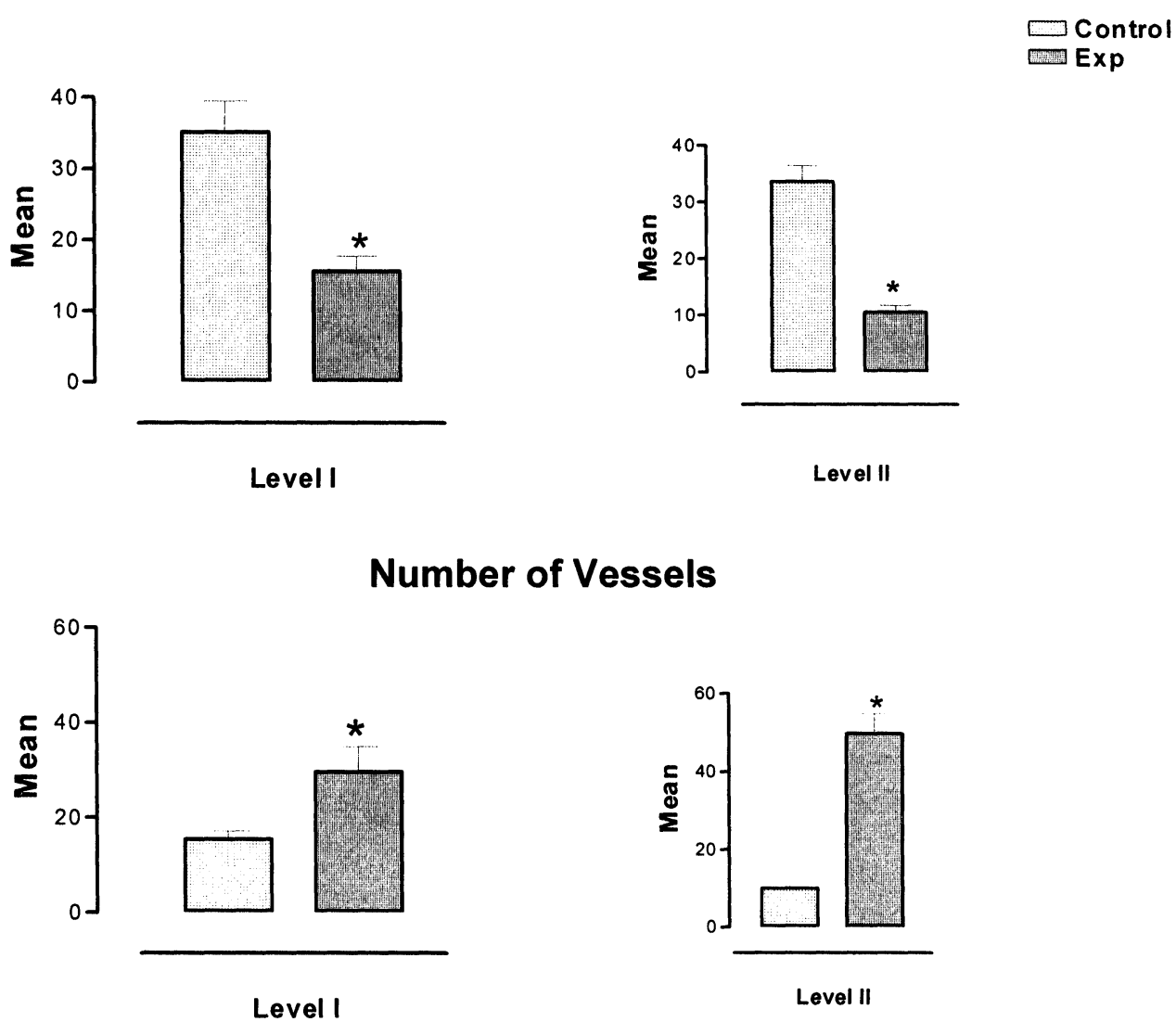

Fig. 4: Mean ( \pm e.p.m.) number of neurons (Top) and vessels (Bottom) in nRt of non-lesioned (Control) and detelencephalated groups (Exp). Measurements were carried out for levels I and II. * $p<0.05$ 
ANOVA confirmed significant between-group differences in response rates $\left(F_{1,13}=7,57 ; p=\right.$ $0.016515)$ and indicated significant interaction among stimuli, condition and session $\left(\mathrm{F}_{5,65}=5,93\right.$; $\mathrm{p}=0.000142$ ). Data relative to the discriminative ratio values showed significant group differences $\left(F_{1,14}=24.77 ; p=0.000203\right)$ as well as significant effects of condition $\left(F_{1,1}=17.52 ; p=0.000916\right)$ and training phase $\left(\mathrm{F}_{1,1}=24.90 ; \mathrm{p}=0.000247\right)$.

In contrast to control birds, showing discriminative ratio values above 0.80 in both conditions, the experimental birds reached indexes above 0.70 in the last discrimination sessions but maintained indexes around 0.50 throughout the reversal condition.

\section{Morphometric Analysis}

Analysis of the number of neuron and vessel.. Figure 4 shows that lesioned birds had a significantly smaller number of intact neuronal somas in the nRt as compared with those of control birds. ANOVA indicated a main effect of
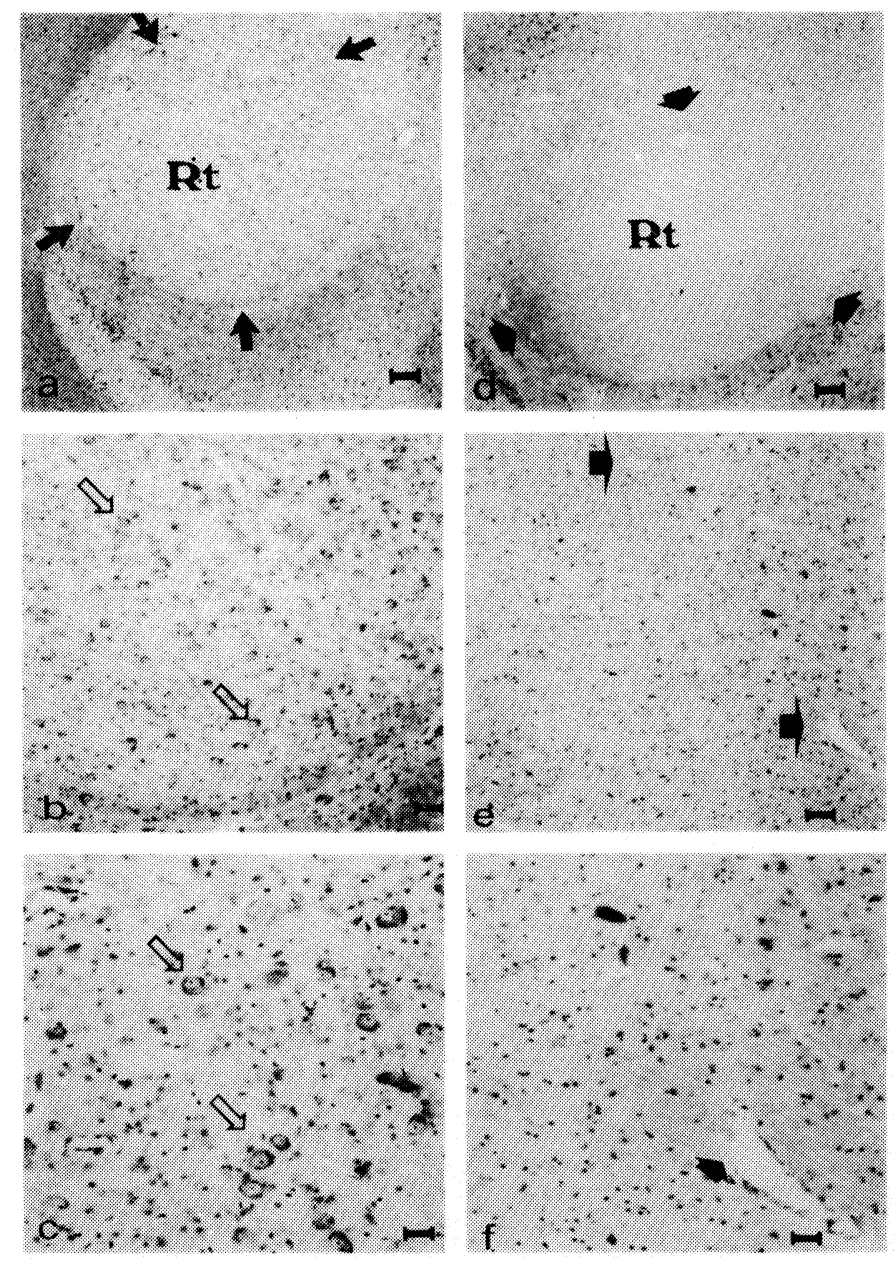

Fig. 5: Microphotographs with frontal sections $(10 \mu \mathrm{m})$ of a control (A-C) and of a telencephalon lesioned brain (D-F). The sections were stained with Klüver-Barrera technique for visualization of myelinated axons. The black arrows indicate the perimeter of $\mathrm{nRt}(\mathbf{a}$ and $\mathbf{d})$ or neuronal bodies (c); white arrows indicate vessels (e and $\mathbf{f}$ ). The lesioned pigeon was sacrificed 120 days after surgery. 
group $\left(F_{1,5}=36.52 ; p=0.00178\right)$. The reduced number of neurons was inversely correlated to a significantly higher number of $\mathrm{nRt}$ vessels, as confirmed by a main effect of group $\left(F_{1,5}=13.09 ; p\right.$ $=0.01525)$ and a significant interaction between group and level of analysis $\left(\mathrm{F}_{1,41}=8.02 ; \mathrm{p}\right.$ $=0.036592$ ). The photomicrographs (See Fig. 5) show lesioned and control brains, with details of neuronal bodies, fiber patterning and vessels.

\section{Rotundus Perimeter}

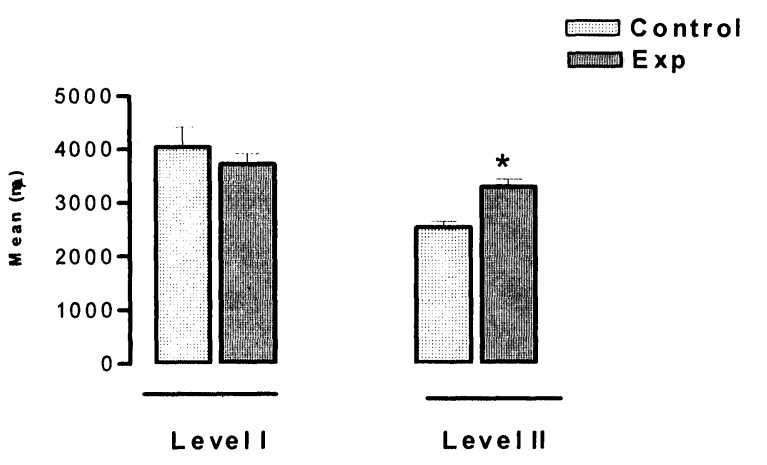

1 Optic Tectum Perimeter

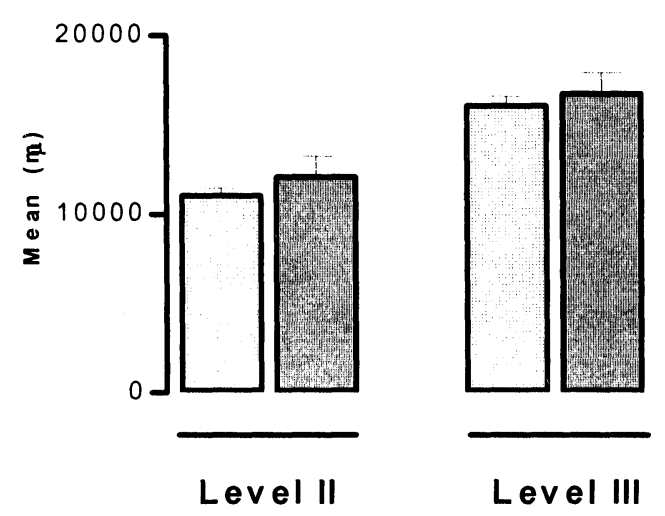

Fig. 6: Mean ( \pm e.p.m.) perimeter $(\mu \mathrm{m})$ values for $n$. Rt - levels I and II (Top)-, and for OT - levels II and III (Bottom)- of control (Control) and detelencephalated groups (Exp).
Rotundus and optic tectum perimeters. Figure 6 shows the data relative to the mean perimeter values $(\mu \mathrm{m})$ of the $\mathrm{n}$. Rt (Top) and the Optic Tectum (Bottom) in control and lesioned birds. Lesioned birds had increased perimeter in the level II of $n$. Rt as compared with controls (see also Fig. 5). This result was confirmed by ANOVA as a main effect of level $\left(F_{1,1}=91.41 ; p=0.000212\right)$ and a significant interaction between group and level $\left(F_{1,41}\right.$ $=70.38 ; \mathrm{p}=0.000394$ ).

Analysis of the Optic Tectum layers. Figure 7 shows the data of mean of thickness $(m \mu)$ of the OT layer 1 and 2 for control and experimental groups. The differences observed in layer 1 were confirmed by ANOVA as a main effect of group $\left(F_{1,5}=10.36 ; p=0.023495\right)$ and level of analysis $\left(F_{1,1}=12.08 ; p=0.017738\right)$. No significant differences were observed in the data of layer 2 $(p>0.05)$. In contrast, a clear disorganization of the layer cell pattern that is characteristic of the OT was seen in lesioned birds (Fig. 9) as compared with controls (Fig. 8). The disorganization of both the cell bodies' dispersion and the patterns of axonal orientation was so intense that the precise identification of layers $3,4,5$, and 6 was impossible.

\section{DISCUSSION}

The data of the present study provide behavioral and neural evidence that may be considered as important indication of processes of neural plasticity. The behavioral data indicated that detelencephalated pigeons are capable of operant discriminative relations learning when (1) they have longer training than the controls and (2) are exposed to one particular kind of response contingencies, although (3) they are devoid of the capacity for reversal learning when these response contingencies are interchanged. So, the present data indicate that the telencephalon plays a crucial 


\section{Optic tectum}

\section{Layer I}

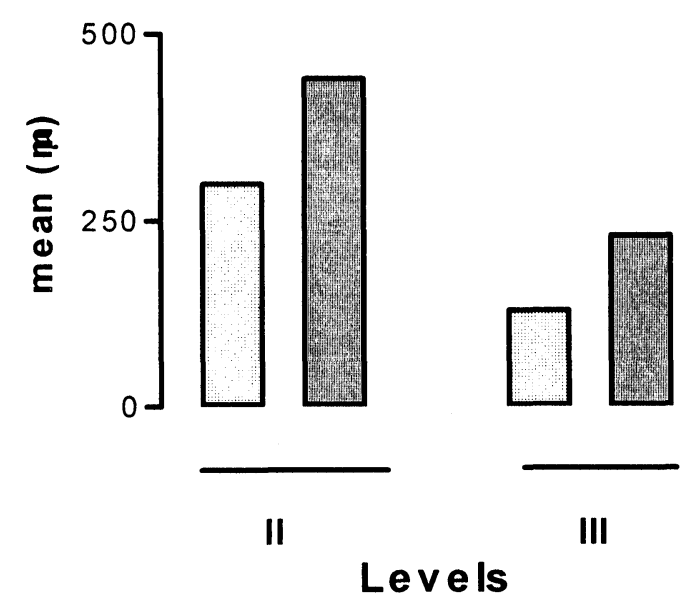

Layer II

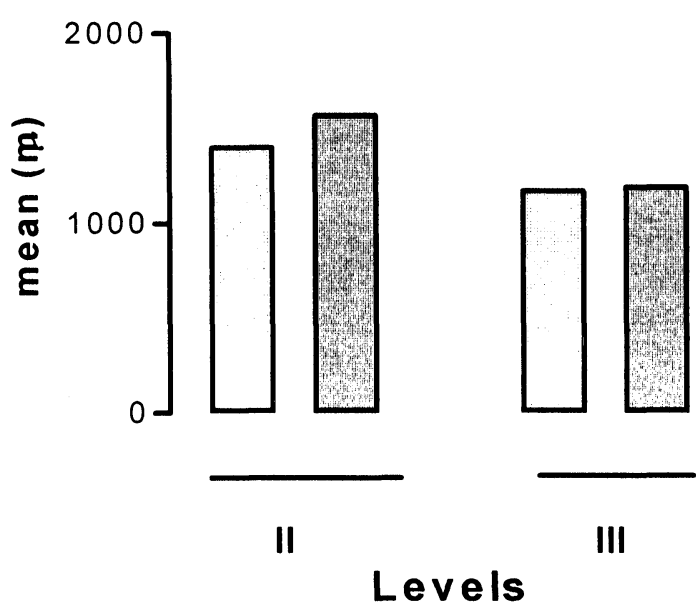

Fig. 7: Mean ( \pm e.p.m.) of thickness $(\mu \mathrm{m})$ of OT layers 1 and 2 of control (Control) and detelencephalated groups (Exp). Measurements refer to levels of analysis II and III. role in the reversal or reorganization of the relations between events/ stimuli, as well as between stimuli and behavior. However, it is not essential for the acquisition of particular discriminations, that is, when they are first learned.

Evidence of long-term changes in the neuroanatomical substrates after detelencephalation was provided by morphometric data showing that (1) lesioned birds had a significant increase in the thickness of layers 1 and 2 of OT relative to control animals, as well as (2) a large decrease in the number of neurons in the $\mathrm{nRt}$ associated to an expressive increase in the vascularization of this region.

The acquisition of discriminative responsestimulus relationships occurred in the absence of the avian telencephalon although requiring longer training. In the discrimination condition, the longterm follow up of key pecking rates until steadystate discriminative behavior provided evidence of processing and long-term storage of information in the subtelencephalic structures. The different stimulus conditions and the contingencies of reinforcement correlating with each of the components were discriminated. This was demonstrated by a higher rate of key pecking response concentrated in the Red component, the one associated with food reinforcement and conforms to previous data of the literature (Mackintosh, 1977; Terrace, 1966).

In contrast, even after long-term training in reversal discrimination, there was no evidence of differential responding to the yellow and red keys by the lesioned birds. DR values increased to 0.50 in the sixth acquisition session and similar values were maintained during the criterion sessions. These DR values demonstrate that the increases in the rates of responding to yellow seen in Exp group were accompanied by sustained high key peck rates in red. The results indicate that operant stimulus control can be established during discrimination 
learning in pigeons lacking the telencephalic structures, but cannot be completely reversed. Although previous studies (Chaves \& Hodos, 1998; Hartmann \& Güntürkün, 1998; López, et al., 2000; Macphail, 1971; Sttetner, 1974; Shimizu \& Hodos, 1989) already showed impairment of reversal learning after restrict telencephalic lesions, is worth saying that brain function and plasticity after injury are associated with a number of factors as size and topography of the lesion (Irle, 1990). Therefore, our data add new information concerning the effects of massive lesion of telencephalon on reversal learning that may be interesting when analyzed in the context of neural plasticity.
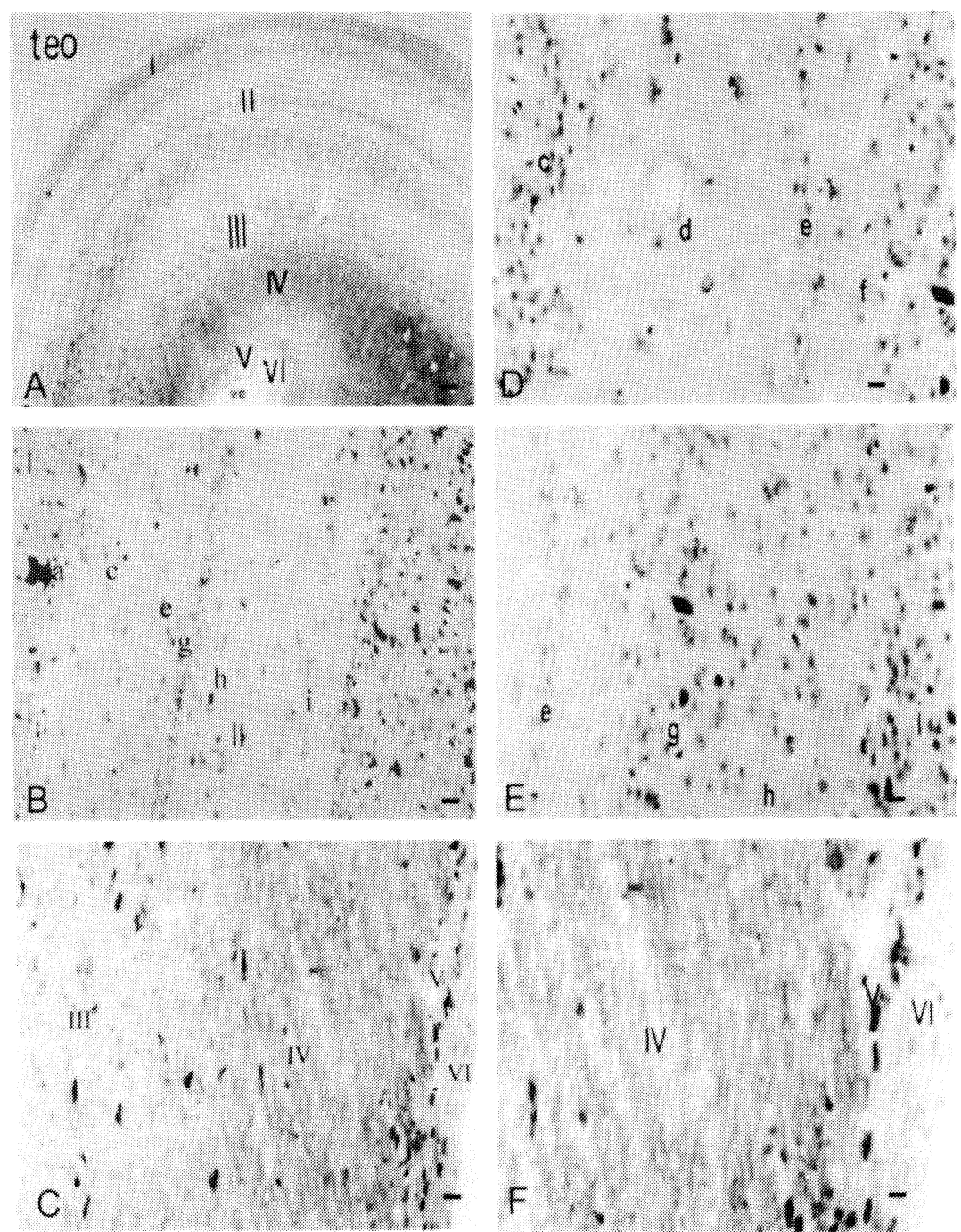

Fig. 8: Microphotographs showing OT in frontal section (10um) in the brain of one non lesioned pigeon (Control). Cell bodies and myelinated fibers were visualized using Klüver-Barrera technique. The animals were sacrificed 120 days after surgery. Layer I - IV (A-C) layer II (a-j) (D-E) and layer II(g-I) and layer III (F). A=10 $\mu \mathrm{m} ; \mathbf{B}=$ $20 \mu \mathrm{m} ; \mathbf{C}=40 \mu \mathrm{m} ; \mathbf{D}, \mathbf{E}, \mathbf{F}=100 \mu \mathrm{m}$ 
Moreover, our results suggest that retrieval and utilization of information relative to reversal learning requires integrative processes between telencephalic and subtelencephalic systems. Normally, learning new functional relationships between already known stimulus or response classes - that is, reversal learning-is certainly accomplished by information processing and rewiring of neural circuits, presumably, in the telencephalic systems. At a later time, the information regarding the reversed contingencies relations may be stored in subtelencephalic circuits. We might suppose, then, that the essential circuits/mechanisms for changes in stored information occur in telencephalic circuits and when these are inoperative, the previously established relations do not change.

The characteristics of behaviors exhibited by
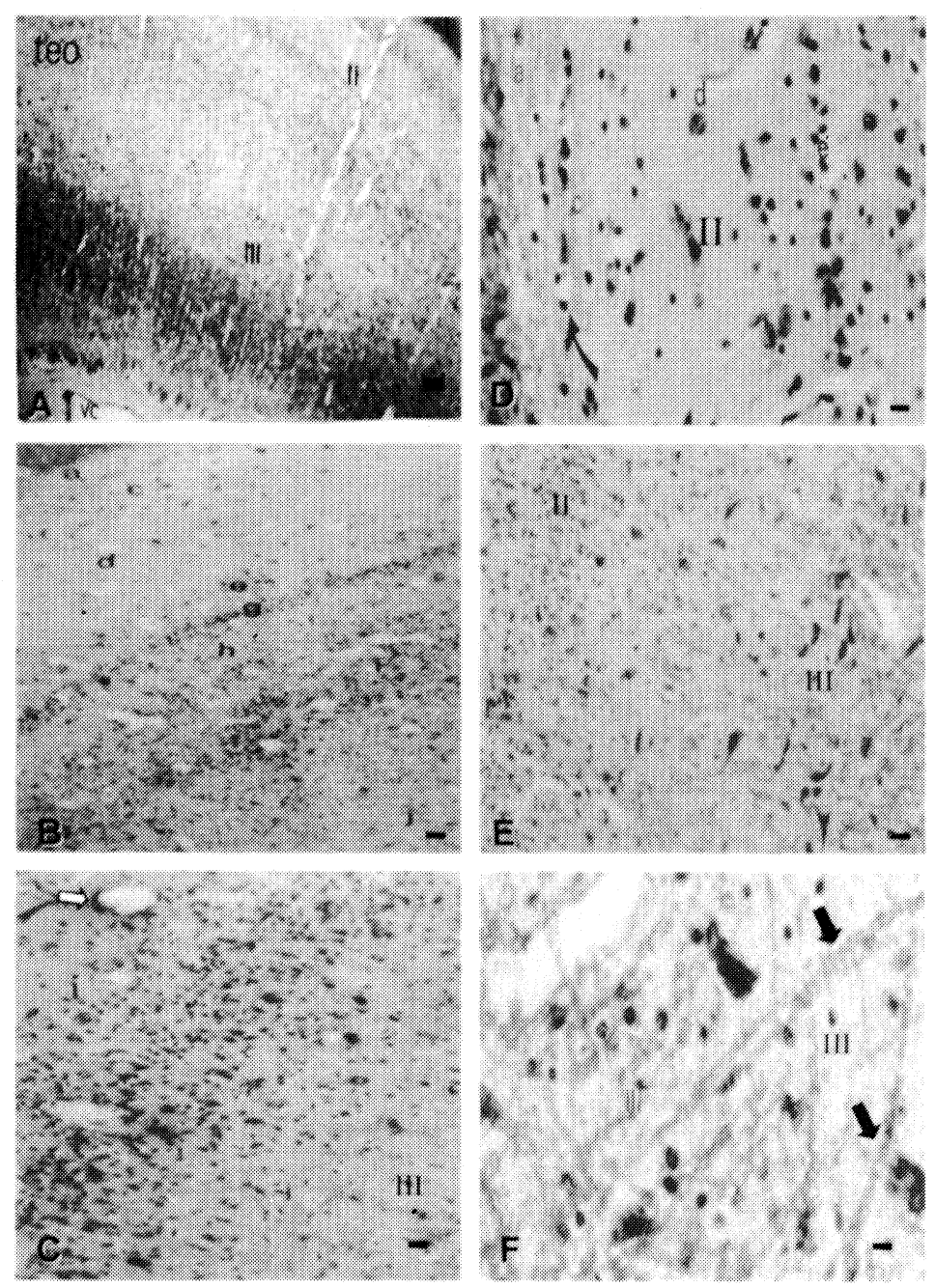

Fig. 9: Microphotographs showing OT in frontal section (10um) in the brain of one pigeon submitted to detelencephalation lesion (Exp). Cell bodies and myelinated fibers were visualized using Klüver-Barrera technique. Layer I - VI (A) layer II (B, C, D, E), layer III (C, E, F). Subdivisions of layer II are directly indicated by letters a-j. The animals were sacrificed 120 days after surgery. $\mathbf{A}=10 \mu \mathrm{m} ; \mathbf{B}, \mathbf{C}=20 \mu \mathrm{m} ; \mathbf{E}=40 \mu \mathrm{m}$; $\mathbf{D}, \mathbf{F}=100 \mu \mathrm{m}$. 
detelencephalated birds also point out the role of the telencephalon in the coordination of the sequence and patterns of responding (Souza, et al, 1990). As we reported before, pigeons with massive ablation of the telencephalon require a longer training during the process of key-pecking shaping, as compared with control pigeons, as well as longer discrimination training to meet the steady-state criterion (Cerutti \& Ferrari, 1995). The diversity and elevated frequency of behaviors in the experimental chamber together with the delayed detection and responding to the key stimulus, might have affected, primarily, the performance of lesioned pigeons. That is, these facts suggest that birds lacking the telencephalic neural systems demonstrated impaired coordination and regulation of behavior during operant training. When considering the arguments concerning disruption of attention processes caused by telencephalic lesions in birds (Mackintosh, 1977; Voytko, 1996), worth remembering is that the experimental pigeons were able to acquire and to maintain key-peck responding under different contingencies of reinforcement. Despite a lack of a satisfactory explanation of the characteristics of behavior after massive damage to the telencephalon, we suggest that the functional role of the remaining structures is remarkable. Along the training situations, subtelencephalic systems were in charge of the mechanisms related to the processing, storage, and retrieval of associative information, underlying the operant discriminative learning by pigeons.

The ability to identify and to recognize stimuli, as well as the contingency relations between stimuli and responses is necessary for discrimination learning be accomplished. Stimulus identification and categorization requires sensorial processing in different levels of the central nervous system. Telencephalic lesions impair the integration and modulation of the subtelencephalic sensorial processing. Thus, the operant discriminative behavior of detelencephalated pigeons results from sensorial processing of stimulus as well as from complex integrative mechanisms carried out at the subtelencephalic level. Therefore, the operant discriminative behavior of detelencephalated pigeons is devoid of both inhibitory and excitatory telencephalic controls. Indeed, even localized lesions in the Wulst complex (Macphail, 1971; Hodos, 1969) and the ectoestriatum (Bessette \& Hodos, 1989; Hodos, et al., 1988) have been related to changes in behaviors during training in tasks using discrimination of intensity, depth or color dimensions. Lesion in the archistriatal complex results in increased response rates in variable-interval schedules of reinforcement (Zeier, 1968). It may, thus, be considered extraordinary that operant discrimination learning takes place in detelencephalated pigeons. Pecking behavior is organized in the brainstem. Suppression of brainstem pecking centers is likely to involve the activation of the nigroestriatal dopaminergic circuits (Csillag, 1999). The mechanisms that are activated to support this capacity still remain to be completely understood.

To further understand the peculiarities of the subtelencephalic structures participating in these processes, the present study also focused on the morphometric analysis in two relay stations of the visual pathways. The important role of telencephalic structures as target areas of the information processed at subtelencephalic levels is well known. Lesions of the thalamofugal pathway have little or no effect on discriminative learning (Hodos \& Bonbright, 1974). In contrast, the tectofugal pathway makes an important contribution to the specific cognitive process. The telencephalic structures target the tectofugal system, from retina to ectostriatum, via two important relays, namely the optic tectum (OT) and the nucleus rotundus (n. Rt) (Shimizu \& Bowers, 1999; Güntürkun \& Hahmann, 1999). The OT description based on connections and physiological characteristics 
considers six cytoarchitetonic distinct layers, clearly arranged with alternating fibrous and cellular layers (Hüber \& Crosby, 1929; Heidmann \& Luksuch, 2001). The laminar arrangement is characterized, and the retina axons turn to the appropriate laminar site within the tectum, layer 1. Layer 2 is distributed in the major area in the OT, where intra-optic connections are established and the efferent axons of the Wulst are concentrated. Thus, layer 2 can be divided into 10 distinct layers based on the targets of theirs projections. Neurons of tectal layer 4, project bilaterally into $n$. Rt. The bilateral projection is very important because the Rt may integrate both sides of the visual information. Actually, the avian $\mathrm{nRt}$ is compared to the primate pulvinar as the primary recipient of the tectal efferents (Karten \& Hodos, 1970; Karten, et al., 1997; Shade \& Powers, 1969; Shimizu \& Bowers, 1999).

As shown by the present data, both the OT and the nRt had significant structural disorganization after detelencephalation. The morphometric data clearly show a pattern of cellular arrangement in the OT that entirely contrasts with the very well organized pattern of the cellular layer normally seen in this structure. The compensatory changes in the nRt and OT can be explained by a reorganization of neural connections. Thus in the OT, the significant increase in the thickness of layers 1 and 2 indicate an altered pattern of afferent visual fibers that can be related to an amplification of the transmission of visual information both to mesencephalic and diencephalic visual neurons. A large decrease in the number of neurons in the $\mathrm{nRt}$ was found, as well as an expressive increase in the vascularization of this region. As the number of target thalamic neurons decreased, we might suppose a higher neuronal convergence at the thalamic level. Synaptic reorganization was suggested by the finding that lesioned birds presented a scattered distribution of the cell bodies and irregular axonal projections intra and between the cell layers of the OT. Another consequence of injury is a disruption of communication between healthy neurons. This event can lead to neuronal degeneration and cell death (Cerutti \& Chadi, 2000; Horner \& Gage, 2000).

The data presented here provide evidence of extensive neural reorganization after such longterm lesion, which when added to the behavioral and learning characteristics of the detelencephalated birds, can be considered as an important indication of processes of neural plasticity. The increased vascularization in the $\mathrm{n}$. Rt, the widening of the layer 1 of the OT, as well as the evidence of a probable synaptic reorganization might indicate functional compensation. The observed pattern of cell and axonal arrangement and the alterations in cell number might represent reorganizational processes for the maintenance of functional capacity.

Another point worth considering is the role of glial cells in such a condition of neural reorganization. CNS functional regeneration strategies require multi-step processes. Growing evidence demonstrates the existence of a close bi-directional brain communication system between neurons, glial cells, and endothelial cells (Carmignoto, 2000; Jiang, et al., 1995). The reactive hyperplasia of astrocytes and their hypertrophy are common phenomena, observed either close or distant from the site of injury (Cerutti \& Chadi, 2000). Certain studies have suggested that astrocytes have an influence in vasculogenesis and astroglial cells are known to produce endothelial cells growth factors (Gomes, et al., 2001; Saadoun, et al., 2002). These observations suggest that reactive astrocytes may influence vascuologenesis after detelencephalation.

Much has been said about telencephalic functions. Studies on the organization of the telencephalon show that the functional similarity between birds and mammals is greater than was supposed decades ago (Aldavert-Vera, et al., 1999; Hartmann \& Güntürkün, 1998; Mogensen \& Divac, 1993). Indeed, its important role in learning 
is well documented. The present study provides interesting data concerning the avian capacity of sensorial processing of information in the absence of the telencephalon. Moreover, that detelencephalated pigeons did not show acceptable discrimination indexes in the situation of reversal learning characterizes a learning deficit and points to the importance of telencephalic systems for the integration of new and old information and for the dynamic evaluation of organism/environment interactions. Conversely, that they were capable of learning the initial discrimination characterizes a learning capacity that is independent of telencephalon integrity and points to the importance of the subtelencephalic systems for processing and storing of associative information.

\section{ACKNOWLEDGEMENTS}

We are grateful to W.L. Gomes for technical assistance and help with the daily experimental procedures, A. Aguilar for her attention and kindness in introducing me to the morphometrical methodology, and to A.S. Vieira for his help with the graphic art. Histological analyses were improved thanks to clues kindly provided by C.A. Netto, to whom we are indebted. This work is part of a doctoral thesis presented by S.M. Cerutti ao Departamento de Fisiologia e Biofísica, IB, UNICAMP in partial fulfillment of the requirements for the $\mathrm{PhD}$ degree. S.M. Cerutti was the recipient of FAPESP and CAPES Fellowships.

\section{REFERENCES}

Aldskogius H, Kozlova E. 1998. Central neuron-glial and glial-glial interactions following axon injury. Prog Neurobiol 55: 1-26.
Andrzejewisk ME, Field DP, Hineline PN. 2001. Changing behavior within session: cyclicity and perseverance produced by varying the minimum ratio of a variable-ratio schedule. Exp Anal Behav 75: 235-246.

Aldavert-Vera, L, Costa-Miserachs D, Divac I, Delius JD. 1999. Presumed "prefrontal cortex" lesion in pigeons: effects on visual discrimination performance. Behav Brain Res 102: 165-170.

Bessete BB, Hodos W. 1989. Intensity, color and pattern discrimination deficits after lesion of the core and belt regions of the ecto-estriatum. Visual Neurosci 2: 27-34.

Berntson GG, Tuber DS, Neve RL, Bachman. 1983. The decerebrate human: associative learning. Exp Neurol 81: 77-88.

Britto LRG. 1978. Inhibition of tectal neurons from telencephalic visual areas in pigeons. Rev Bras Pesqui Med Biol 11: 223-227.

Brunelli M, Magni F, Moruzzi, G Musumeci O. 1972. Brain stem influences on waking and sleep behavior in the pigeon. Arch Itallien de Biol 110: 285-321.

Carmignoto G. 2000. Reciprocal communication systems between astrocytes and neurons. Prog Neurobiol 62: 561-581.

Cavaglia M, Dombroswki SM, Drazba J, Vasanji A, Bokeesch PM, Janigro D. 2001. Regional variation in brain capillary density and vascular response to ischemia. Brain Res 910: 91-93.

Cerutti SM, Ferrari, EAM. 1995. Operant discrimination learning in detelencephalated pigeons (Columba livia). Brazilian J Med Biol Res 28 : 1089-1095.

Cerutti SM, Chadi G. 2000. S100 immunoreactivity is increased in reactive astrocytes of the visual pathways following mechanical lesion of the rat occipital cortex. Cell Biol Intern 24: 35-49.

Chaves LM, Hodos W. Color reversal-learning deficits after tectofugal pathways lesions in the pigeon telencephalon. Behav Brain Res 1998. 90: 1-12.

Chen P, Goldberg DE, Kolb B, Lanser M, Benowitz LI. 2002. Inosine induces axonal rewiring and provides behavioral outcome after stroke. Proc Natl Acad Sci 99: 9031-9036.

Colombo M, Frost N, Steedman W. 2001. Response of ectoestriatal neurons during delayed matchingto-sample behavior in pigeons (Columba livia) Brain Res 917: 55-66. 
Csillag A. 1999. Striato-telencephalic and striatotegmental circuits: relevance to learning in domestic chicks. Behav Brain Res. 98: 227-236.

Delay ER. 2001. Cross-modal transfer effects on visual discrimination depend on lesion location in the rat visual system. Physiol Behav 73: 609-620.

Eacott MJ, Machin, PE, Gaffan EA. 2001. Elemental and configural visual discrimination learning following lesions to perirhinal cortex in the rat. Behav Brain Res 124: 55-70.

Fawcett JW, Ascher RA. 1999. The glial scar and central nervous system repair. Brain Res Bull 49: 377-391.

Ferrari EAM, Faleiros L, Cerutti SM, Oliveira AM. 1999. The functional value of sound and exploratory behavior in detelencephalated pigeons. Behav Brain Res 101: 93-103.

Finger S, Almli CR. 1985. Brain damage and neuroplasticity: mechanism of recovery or development? Brain Res Rev 10: 177-186.

Fróes MM, Carvalho ACC. 1998. Gap junctionmediated loops of neuronal-glial interactions. Glia 24: 97-107.

Gaffan D, Easton A, Parker A. 2002. Interaction of inferior temporal cortex with frontal cortex and basal forebrain: double dissociation in strategy implementation and associative learning. $\mathrm{J}$ Neurosci 22: 7288-7296.

Giordana MT, Attanasio A, Cavalla P, Migheli A, Vigliani MC, Schiffer D. 1994. Reactive cell proliferation and microglia following injury to the rat brain. Neuropath Applied Neurobiol 20: 163 174.

Gomes FCA, Spohr TCLS, Martinez, Neto VM. 2001. Cross-talk between neuron and glials: highlights on soluble factors. Braz J Med Biol Res 34: 611-620.

Good M. 1978. The effects of hippocampal-area parahippocampalis lesions on discrimination learning in the pigeons. Behav Brain Res 26: 171-184.

Granados-Rojas L, Larriva-Shade J, Cintra L, GutierrezOspina G, Rondan A, Diaz-Cintra S. 2002. Prenatal protein malnutrition decreases mossy fibers-CA3 thorny excrescences asymmetrical synapses in adult rats. Brain Res 933: 164-171.

Güntükün $\mathrm{O}$, Diekampb, Manns, M, Nottelman F, Prior H, Schwarz A, Skiba M. 2000. Asymmetry pays: visual lateralization improves discrimination success in pigeons. Curr Biol 17: 1079-1081.

Güntükün O, Hahmann U. 1999. Functional sub- divisions of the ascending visual pathways in the pigeons. Behav Brain Res 98: 193-201.

Hartmann B, Güntürkun O. 1998. Selective deficits in reversal learning after neostriatum caudolateral lesions in pigeons: Possible behavioral equivalencies to the mammalian prefrontal system. Behav Brain Res 96: 125-133.

Heaton MB, Gallheher EL, Baker RT, Otero J, Alvarez IM. 1981. Operant escape learning in decerebrate duck (Ana platyrhynchos). J Comp Physiol Psychol 5: 199-204.

Heidmann S, Lucksch H. 2001. Development of retino-recepient projection neurons in the optic tectum of the chicken. Development Brain Res 128: 149-156.

Hellmann B, Güntürkün O. 1999. Visual-field-specific heterogeneity within the tecto-rotundal projection of the pigeon. Eur J Neurosci 11: 2635-2650.

Hodos W, Karten HJ. 1966. Brightness and pattern discriminations deficits in the pigeons after lesions in the nucleus rotundus. Exper Brain Res 2: $151-167$.

Hodos W. 1969. Color discrimination deficits after lesions of the nucleus rotundus in the pigeons. Brain Behav Evol 2: 185-200.

Hodos W. 1970. Visual intensity and pattern discrimination deficits after lesions of ectostriatum in pigeon. J Comp Neurol 140: 53-68.

Hodos W, Bonbright JC. 1974. Intensity difference thresholds in pigeons after lesion of the tectofugal and thalamofugal visual pathways. J Comp Physiol Psychol 87: 151-167.

Hodos W, Macko KA, Bessette B. 1984. Near field acuity changes after visual system lesion in pigeons. II Telencephalon. Behav Brain Res 13: 15-20.

Hodos W, Weiss RB, Bessette B. 1988. Intensity difference thresholds after lesions of ectostriatum in pigeons. Behav Brain Res 30: 45-53.

Horner PJ, Gage FH. 2000. Regenerating the damaged central nervous system. Nature 26: 407: 963-970.

Hüber CG, Crosby EC. 1929. The nuclei and fibers paths of avian diencephalone with consideration of telencephalic and certain mesencephalic centers and connections. J Comp Neurol 48: 1-5.

Hunt SP, Künzle, H. 1976. Observations on the projections and intrinsic organization of the pigeon optic tectum: An auto radiographic study based on anterograde and retrograde axonal and dendritic flow. J Comp Neurol 170: 153-158. 
Huston JP, Tomaz C, Fix T. 1985. Avoidance learning in rats devoid of telencephalon plus thalamus. Behav Brain Res 17: 87-99.

Huston JP, Tomaz C. 1986. Subtelencephalic locale of reinforcement and learning: looking for the minimal necessary structures. Behav Brain Res 22: $153-161$.

Irle E. 1990. An analysis of the correlation of lesion size-localization and behavioral effects in 283 pubished studies of cortical and subcortical lesions in old-world monkeys. Brain Res Rev 15: 181-213.

Jeglinki W, Koczyk D, Zaremba M, Oderfeld-Nowak B. 1995. Bilateral gliosis in unilaterally lesioned septohippocampal system: changes in GFAP immunoreactivity and content. J Neurosci Res 41 : 394-402.

Jiang b, Bezhadian A, Caldwell RB. 1995. Astrocytes modulate retinal vasculogenesis: effects on endothelial cell differentiation. Glia 15: 1-10.

Karten HJ. 1967. A Stereotaxic Atlas of the Brain of the Pigeon (Columba livia). Baltimore, Maryland, USA: Johns Hopkins Press.

Karten HJ. 1965. Projections of the optic tectum of the pigeon (Columba livia). Anat $\operatorname{Rec} 148$ : 297-298.

Karten HJ, Hodos W. 1970. Telencephalic projections of the nucleus rotundus in the pigeon (Columba livia). J Comp Neurol 140: 35.

Karten HJ, Revzin MA. 1960. The efferent connections of the nucleus rotundus in the pigeon. Brain Res 2: 368-377.

Karten HJ, Hodos W, Nauta JW, Revzin MA. 1973. Neural connections of the "visual Wulst" of the avian telencephalon. Experimental studies in pigeon (Columba livia) and owl (Speotyto canicularia). J Comp Neurol 150: 253-278.

Karten HJ, Cox K, Mpodozis J. 1997. Two distinct populations of tectal neurons have unique connections within the retinotectorotundal pathway of the pigeon (Columba livia). J Comp Neurol 387: 449-465.

Klüver H, Barrera E. 1953. A method for the combined staining of cells and fibers the nervous system. J Neuropathol Exp Neurol 12: 400-403.

Kolb B, Whishaw I. 1989. Plasticity in the neocortex: Mechanisms underlying recovery from early brain damage. Progress Neurol 33: 235-276.

Kolb B, Whishaw I. 1998. Brain Plasticity and behavior. Annu Rev Psychol 49: 43-64.

Laverghetta AV, Shimizu T. 1999. Visual discrimin- ation in the pigeon (Columba livia): effects of selective lesions of the nucleus rotundus. Neuroreport 10: 981-985.

Lawrence AD, Sahakian BJ, Rogers RD, Hodges JR, Robbins TW. 1999. Discrimination, reversal, and shift learning in Huntington's disease: mechanisms of impaired response selection. Neuropychol 37: 1359-1374.

Le Vére TE. 1980. Recovery of function after brain damage: A theory of behavioral deficit. Physiol Psychol 8: 297-308.

Levine RR, Zeigler HP. 1981. Extratelencephalic pathways and feeding behavior in the pigeon Columba livia. Brain Behav Evol 19: 56-92.

López JC, Broglio, C, Rodríguez F, Thinus-Blanc C, Salas C. 2000. Reversal learning déficit in a spatial task but not in a cued one after telencephalic ablation in goldfish. Behav Brain Res 109: 91-98

Mackintosh NJ. 1977. Stimulus control: attentional factors. In: Honig WK, Staddon JER, eds, Handbook of Operant Behavior. Englewoods Cliffs, New Jersey, USA: Prentice-Hall.

Macphail EM. 1971. Hyperestriatal lesions in pigeons: effects on response inhibition, behavioral contrast and reversal learning. J Comp Physiol Psychol 75: 500-507.

Macphail EM, Reilly S, Good, M. 1993. Lateral hyper-striatal lesions disrupt simultaneous but not successive conditional discrimination learning of pigeons (Columba livia). Behav Neurosci 107: 289-298.

McSweeney FK, Murphy ES, Kowal BP. 2001. Within-session changes in responding during concurrent variable interval variable ratio schedules. Behav Proc 55: 163-179.

Mitchell JA. 1983. Paleostriatal lesions in the pigeon (C. livia) potentiate classical conditioning: evidence from fixed-interval responding, freeoperant go no-go discrimination and alternation. Behav Neurosci 97: 171-194.

Mogensen J, Divac I. 1993. Behavioural effects of ablation of the pigeon-equivalent of the mammalian prefrontal cortex. Behav Brain Res 55: 101-107.

Pritz MB, Mead WR, Northcutt RG. 1970. The effects of the Wulst ablation on color brightness and pattern discrimination in pigeons (Columba livia). J Comp Neurol 40: 81-100.

Revzin AM, Karten HJ. 1967. Rostral projections of the optic tectum and nucleus rotundus in pigeons. 
Brain Res 3: 264-275.

Riley NM, Hodos, W, Pasternak T. 1988. Effects of serial lesions of telencephalic components of the visual systems in pigeons. Visual Neurosci 1: 387-394.

Salgado JV, Vidal M, Oberling P, Graeff FG, Danion JM, Sandiner G. 2000. Associative learning and latent inhibition in a conditioned suppression paradigm in humans. Behav Brain Res 117: 53-60.

Saadoun S, Papadopoulos MC, Davies DC, Bell BA, Krishna S. 2002. Increased aquaporin 1 water channel expression in human brain tumours. $\mathrm{Br} \mathrm{J}$ Cancer 87: 621-623.

Shade-Powers A. 1969. Rostral projections of the optic tectum and nucleus rotundus in pigeon. Brain Res 3: 262-276.

Shimizu T, Cox K, Karten HJ. 1995. Intratelencephalic projections of the visual wulst in pigeons (Columba livia). J Comp Neurol 359: 551-172.

Shimizu T, Hodos W. 1989. Reversal learning in the pigeon: Effects of selective lesions of the Wulst. Behav Neurosci 103: 262-278.

Shimizu T, Bowers A. 1999. Visual circuits of the avian telencephalon: evolutionary implications. Behav Brain Res 98: 183-191.

Silva AL, Ferrari EAM. 1991. Massive telencephalic lesions and the organization of behavior in pigeons (Columba livia). Brazilian J Biol Med Res 24: 187-190.

Souza CMZ, Britto LRG, Ferrari EAM. 1990. Key pecking operant conditioning in detelencephalated pigeons (C. livia). Behav Brain Res 38: 223-231.

Stettner LS. The neural basis of avian discrimination and reversal learning. In: Goodman IJ and Schein MW (Editors), Birds Brain and Behavior. New
York, NY, USA: Academic Press; 165-201.

Terrace H. 1966. Stimulus control. In: Honig WK, ed, Operant Behavior: Areas of Research and Applications. New York, NY, USA: AppletonCentury-Crofts.

Toledo CAB, Ferrari EAM. 1991. Habituation to sound stimulation in detelencephalated pigeons (C. livia). Brazilian J Med Biol Res 24: 187-190.

Tomaz C, Huston JP. 1986. Survival of a conditioned inhibitory avoidance response after decerebration. Exp Neurol 93: 188-194.

Torre ER, Lothman, Steward O. 1993. Glial response to neural activity: GFAP-mRNA and protein levels are transiently increased in the hippocampus after seizures. Brain Res 631, 256-264.

Voytko ML. 1996. Cognitive functions of the basal forebrain cholinergic system in monkey: memory or attention? Behav Brain Res 75: 13-25.

Watanabe S. 1999. Effects of hippocampal lesions on spatial operant discrimination in pigeons. Behav Brain Res 103: 77-84.

Watanabe S. 2001. Effects of hippocampal lesions on repeated acquisition of spatial discrimination in pigeons. Behav Brain Res 120: 59-66.

Wesp R, Goodman I. 1978. Fixed interval responding by pigeon following damage to corpus striatal and limbic brain structures (paleostriatal complex and Paraolfactory lobe). Physiol Behav 20: 571-577.

Zeier H. 1968. Changes in operant behavior pigeons following bilateral forebrain lesion. J Com Physiol Psychol 66: 198-203.

Zeier H. 1974. Behavior adaptation on operant schedules after forebrain lesions in the pigeon. In: Goodman IJ, Schein MW, eds, Birds, Brain and Behavior. New York: Academic Press; 153-164. 

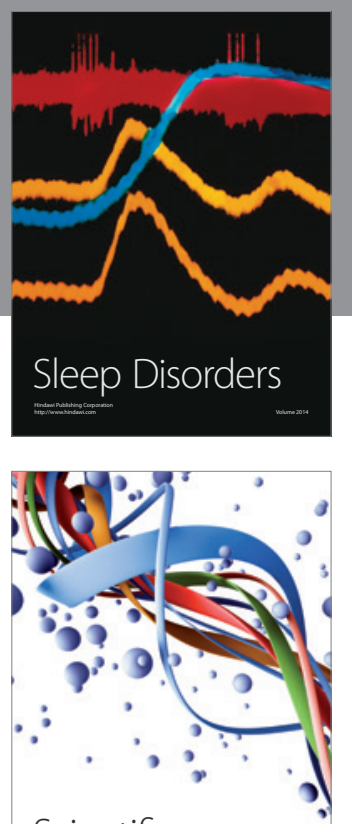

Scientifica
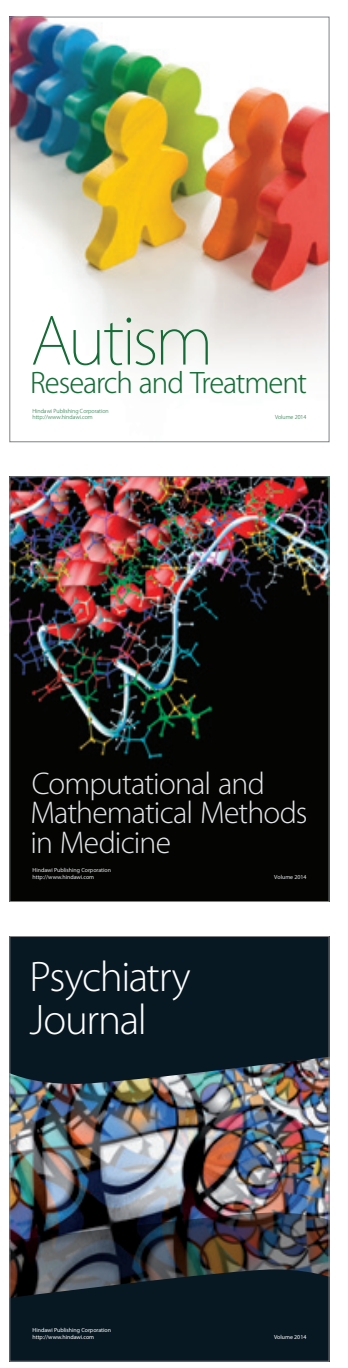
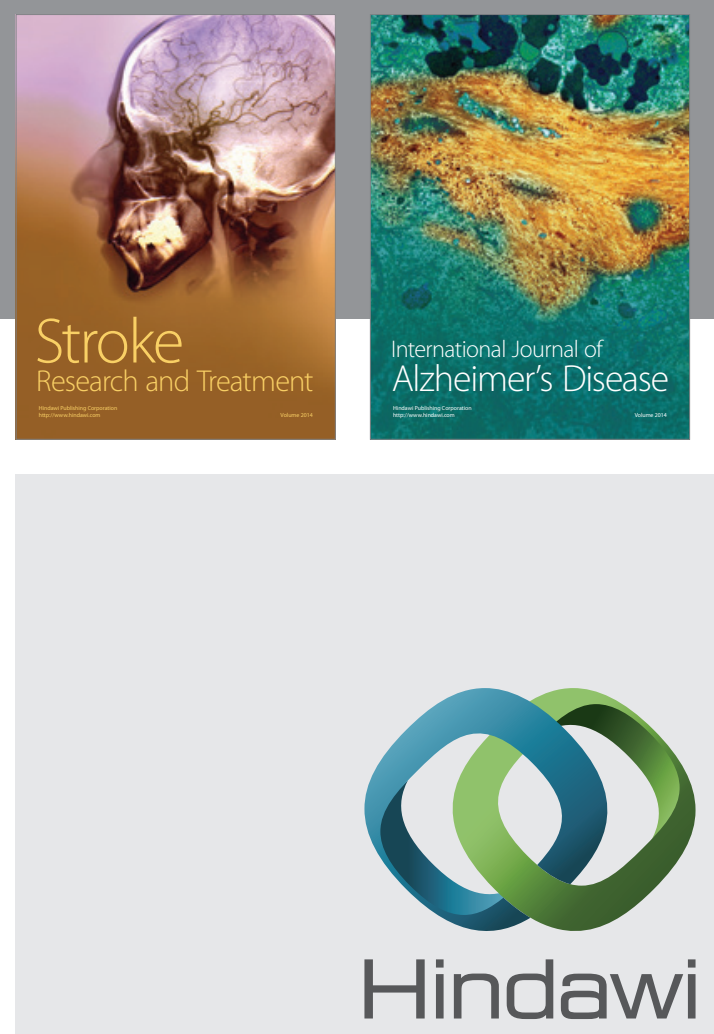

Submit your manuscripts at

http://www.hindawi.com
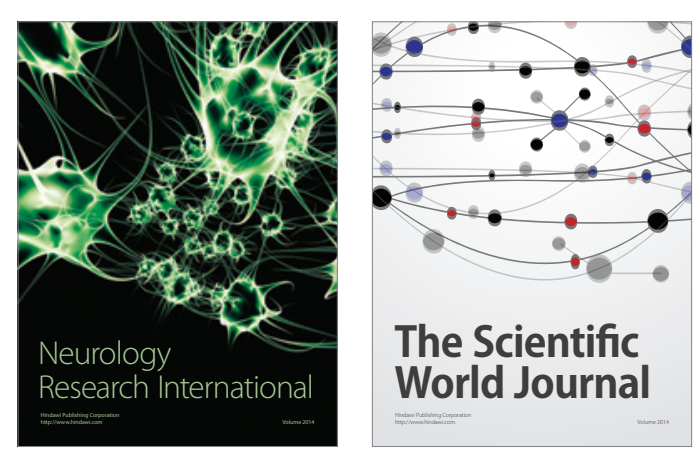

The Scientific World Journal

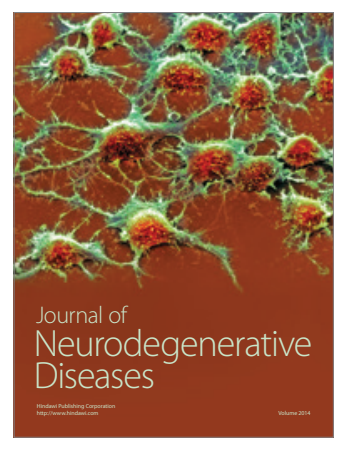

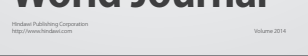

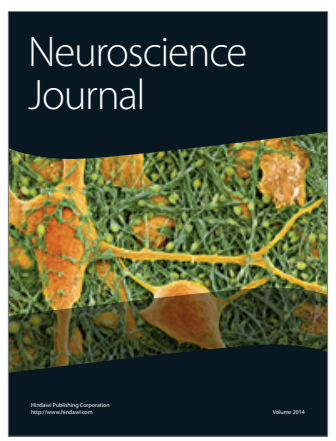

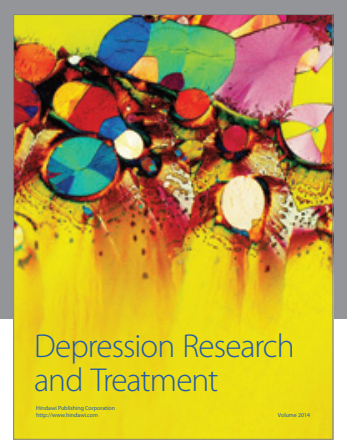
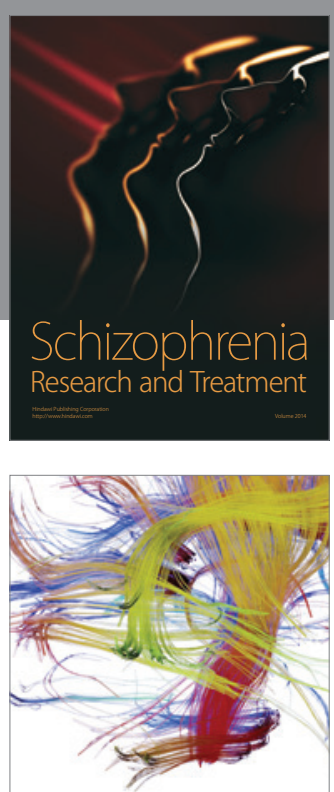

Brain Science

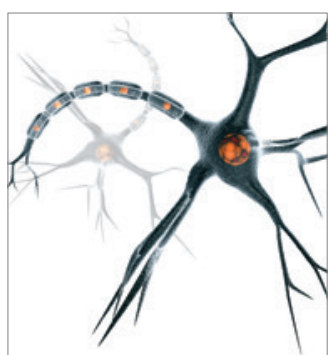

Neural Plasticity
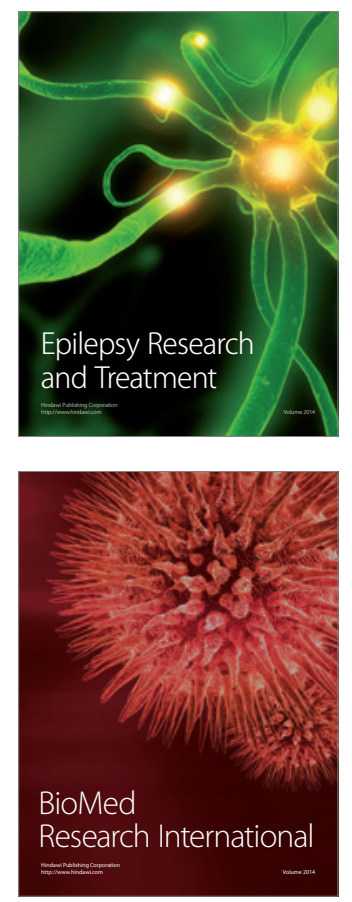

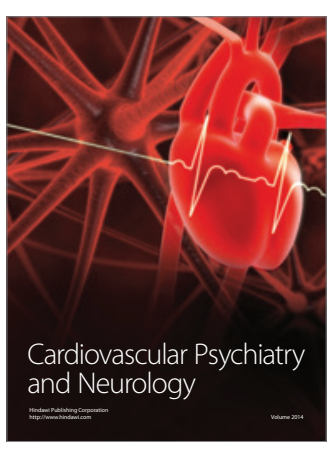

Parkinson's

Disease
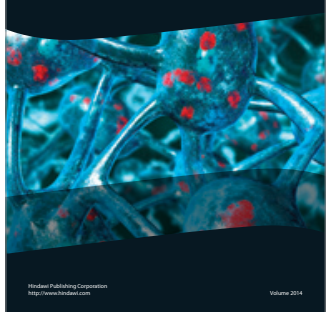